\title{
Fire in the "hall"! Myocardial inflammation and recurrence of atrial fibrillation
}

\author{
Rupak Mukherjee, $\mathrm{PhD}$
}

\footnotetext{
From the Division of Cardiothoracic Surgery, Department of Surgery, Medical University of South Carolina, and Ralph H. Johnson VA Medical Center, Charleston, SC.

R.M. received salary support from a National Institutes of Health grant (AG036954) and a SPiRE award from the Veteran's Administration (I21 RX001707).

Disclosures: Author has nothing to disclose with regard to commercial support.

Received for publication Feb 12, 2016; accepted for publication Feb 19, 2016; available ahead of print March 16 , 2016.

Address for reprints: Rupak Mukherjee, PhD, Division of Cardiothoracic Surgery, MSC 777, 114 Doughty St, Suite 338, Strom Thurmond Building, Charleston, SC 29426 (E-mail: mukherr@musc.edu).

J Thorac Cardiovasc Surg 2016;151:1683-5

0022-5223/\$0.00

Published by Elsevier Inc. on behalf of The American Association for Thoracic Surgery http://dx.doi.org/10.1016/j.jtcvs.2016.02.043
}

An "atrium" - in architectural terms-is defined as an open space to give buildings a "feeling of space and light" from which enclosed rooms lead off. ${ }^{1}$ In that regard, the atrium serves as a "hallway," allowing people to congregate (if needed) and then traverse to different rooms within a structure. Functionally, the atria of the heart-similarlyallow the unimpeded collection of venous blood that is allowed to traverse to the ventricle when the atrioventricular valves open and with atrial contraction (the "atrial kick"). Indeed, the "atrial kick" is considered to contribute an additional $10 \%$ to $20 \%$ to the ventricular volume and, subsequently, ventricular output during normal functioning of the heart. ${ }^{2}$ Cessation of concerted atrial contraction and an irregularly irregular rhythm, as happens with atrial fibrillation (AF), can detrimentally affect ventricular output and contribute to the increased mortality and morbidity and adverse effects on quality of life. ${ }^{3}$ Moreover, the development of AF leads to many structural and functional changes within the atria that perpetuate the arrhythmia, a process known as "electrical remodeling." 3,4 In view of the great burden of AF on health care resources, stable and longlasting (if not permanent) conversion of AF to sinus rhythm using pharmacology, devices, or surgery remains the "holy grail" for AF therapy.

Despite significant advances in our understanding of the electrogenic and structural alterations that occur within the atrial myocardium with $\mathrm{AF}$, long-term restoration of sinus rhythm in all patients with AF remains elusive. Irrespective of whether therapy to restore sinus rhythm was electrical cardioversion, surgical isolation of fibrillatory foci (the Cox Maze procedure), or catheter-based modification of the Maze procedure, AF appears to recur in a substantial proportion of the patients within 1 year of treatment. , $^{3,6}$ Consequently, there has been considerable interest in attempting to determine what factor(s) may be differentially regulated in those patients in whom there is a postprocedural recurrence of $\mathrm{AF}$ versus those who

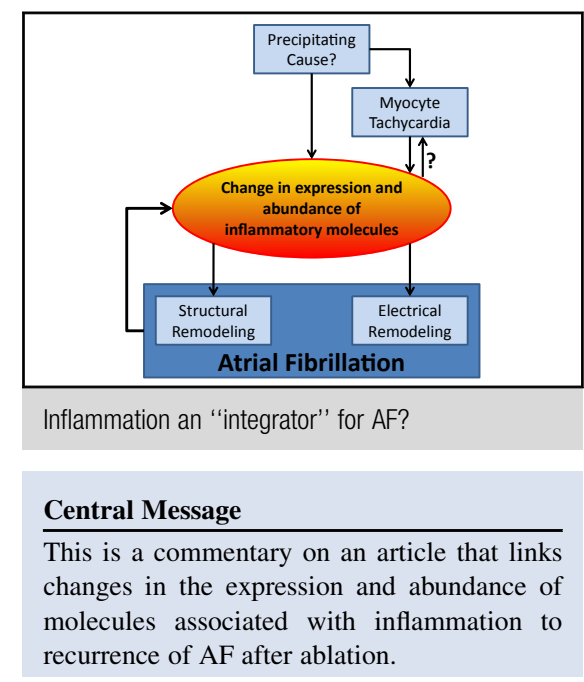

See Article page 1673 .

appear to remain in sinus rhythm. ${ }^{7,8} \mathrm{~A}$ number of bioactive molecules and processes have been identified as potential "contributors" to AF recurrence, as summarized in recent review articles. ${ }^{7,8}$ These processes include proteins and cytokines that are considered to alter electrical properties of atrial myocytes, structural organization of the atrial extracellular matrix, and those molecules generally associated with inflammation.

The role of inflammation in the pathogenesis and recurrence of AF is driven by studies that found increased circulating levels of C-reactive protein in patients with $\mathrm{AF}$, with differentially increased levels in those in whom AF recurred after therapy. ${ }^{7,8}$ Increased abundance of molecules that are considered to be proinflammatory has been reported in atrial biopsies from patients with AF, suggesting that a potential source of the increased circulating levels of these molecules was the atrial myocardium. ${ }^{9}$ Of note, a number of bioactive molecules that are considered to be proinflammatory, including tumor necrosis factor- $\alpha$ and $\mathrm{C}$-reactive protein, have been reported to be predictors of AF recurrence after a therapeutic maneuver to restore sinus rhythm. $8,10,11$

In this issue of the Journal, Tsai and colleagues ${ }^{12}$ present data from a single center where AF ablation was performed by the same surgeon with relatively high volumes (261 procedures over 5 years) and report a $78 \%$ rate of freedom from AF. The ablation procedure was the catheter-based adaptation of the Cox Maze III procedure, 


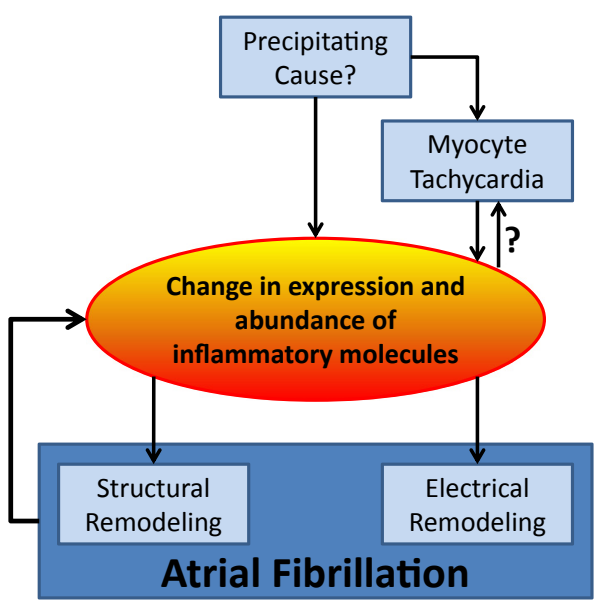

FIGURE 1. Inflammation an "integrator" for AF?

which has been shown to be effective as a means to block abnormal AF circuits. ${ }^{3,6,13,14}$ For the study presented, Tsai and colleagues ${ }^{12}$ obtained consent from 42 patients in whom atrial biopsies were taken at the time of the procedure. Of these patients, AF was found to recur in 12 within 1 year of the procedure, for a recurrence rate of $28 \%$. Because the group in which AF recurred had dilated atria compared with the group in which sinus rhythm was maintained, Tsai and colleagues ${ }^{12}$ performed a post hoc selection of 13 subjects who had atria that were dilated similarly to the recurrence group, for a total of 25 subjects with AF. A group of 10 patients who underwent mitral valve surgery but had no AF served as the non-AF control group. The atrial myocardium was assayed for mRNA expression and protein abundance of a set of inflammation-related targets that may be involved in remodeling of the atria. Although a clear rationale for selecting this subset of "expressed inflammatory genes" from the approximately 35,000 genes we all have is not provided, Tsai and colleagues ${ }^{12}$ report that there were a number of preoperative inflammatory mediators that were differentially regulated in the patients in whom $\mathrm{AF}$ recurred compared with those who remained in sinus rhythm. The authors went one step further-a major strength of this study - and showed that increased rate of electrical stimulation in a cardiac myocyte cell type caused an increase in a subset of the culprit genes. Tsai and colleagues ${ }^{12}$ acknowledge that "this implicates a causative effect of tachyarrhythmia on these genes" rather than the abnormal expression of these genes predisposing to AF recurrence. Thus, their findings for these 4 particular genes may be of little predictive value to determine which patients would be free of AF. Yet, the authors, using receiver operating characteristics analysis, were able to demonstrate that a subset of the differentially expressed genes from the atrial samples may form elements of a predictive panel for $\mathrm{AF}$ recurrence after $\mathrm{AF}$ ablation.
The hypothesis that Tsai and colleagues ${ }^{12}$ test is an intriguing one-and one that is intuitively comfortable: that inflammatory processes provoke atrial dysrhythmias and that these processes at the molecular level are promoted by a series of proinflammatory genes that influence not only the initiation of AF but also the response to surgical and perhaps even pharmacologic therapy. Certain bioactive molecules that were demonstrated to have increased included transforming growth factor- $\beta 1$ and the nuclear factor of activated $T$ cells, both of which are associated with signaling that may alter structural and electrical properties within the myocardium. ${ }^{15-18}$ Taken together, it may be that the changes in the expression and protein of these proinflammatory bioactive molecules form an "integrative" point that feeds forward in the progressive structural and electrical abnormalities that accompany $\mathrm{AF}$ (Figure 1).

However, clinical applicability of the findings from the study by Tsai and colleagues ${ }^{12}$ may be limited. Specifically, it must be recognized that atrial tissue is not easily available before surgical therapy. Thus, if the authors could relate the response to the $\mathrm{AF}$ ablation therapy relative to some reflection of preoperative systemic inflammatory status, the clinical relevance of this study would be dramatically expanded. For example, the authors could have harvested peripheral blood monocytes or neutrophils or even, retrospectively, looked at the preoperative white count or circulating levels of some of the proteins identified in this study as potential markers of AF recurrence.

That being said, precise mechanisms that precipitate the changes in the myocardial levels of these molecules are uncertain and will continue to be explored. Nevertheless, the possibility remains that the local inflammatory response within the atrial myocardium may be causal in the pathogenesis of AF. In that context, increased expression and abundance of these processes that are considered to be proinflammatory may represent the clichéd term, "Fire in the hole!" For those unfamiliar with the term, this phrase originated with miners who used it as a warning for an imminent explosion within a confined space. Whether and to what degree anti-inflammatory agents administered to these patients would be able to "douse" the fire in the anatomic "hall" to the ventricles was not addressed in the study by Tsai and colleagues. ${ }^{12}$ Nevertheless, the results of this hypothesis-driven, mechanistically based, clinically relevant series of investigations, with the identification of candidate molecules, ultimately may provide therapeutic targets for the restoration of sinus rhythm in the setting of AF.

\section{References}

1. Wikipedia.org. Atrium (architecture). Available at: https://en.wikipedia.org/ wiki/Atrium_(architecture). Accessed February 11, 2016.

2. Hall JE. Cardiac muscle; the heart as a pump and function of the heart valves. In: Guyton and Hall Textbook of Medical Physiology. NY: Elsevier; 2016:109-22. 
3. Calkins H, Kuck KH, Cappato R, Brugada J, Camm AJ, Chen SA, et al. 2012 HRS/EHRA/ECAS expert consensus statement on catheter and surgical ablation of atrial fibrillation: recommendations for patient selection, procedural techniques, patient management and follow-up, definitions, endpoints, and research trial design: a report of the Heart Rhythm Society (HRS) Task Force on Catheter and Surgical Ablation of Atrial Fibrillation. Developed in partnership with the European Heart Rhythm Association (EHRA), a registered branch of the European Society of Cardiology (ESC) and the European Cardiac Arrhythmia Society (ECAS); and in collaboration with the American College of Cardiology (ACC), American Heart Association (AHA), the Asia Pacific Heart Rhythm Society (APHRS), and the Society of Thoracic Surgeons (STS). Endorsed by the governing bodies of the American College of Cardiology Foundation, the American Heart Association, the European Cardiac Arrhythmia Society, the European Heart Rhythm Association, the Society of Thoracic Surgeons, the Asia Pacific Heart Rhythm Society, and the Heart Rhythm Society. Heart Rhythm. 2012;9: 632-96.e21.

4. Wijffels MC, Kirchhof CJ, Dorland R, Allessie MA. Atrial fibrillation begets atrial fibrillation. A study in awake chronically instrumented goats. Circulation. 1995;92:1954-68.

5. Mukherjee R, Akar JG, Wharton JM, Adams DK, McClure CD, Stroud RE, et al. Plasma profiles of matrix metalloproteinases and tissue inhibitors of the metalloproteinases predict recurrence of atrial fibrillation following cardioversion. $J$ Cardiovasc Transl Res. 2013;6:528-35.

6. Prasad SM, Maniar HS, Camillo CJ, Schuessler RB, Boineau JP, Sundt TM 3rd, et al. The Cox maze III procedure for atrial fibrillation: long-term efficacy in patients undergoing lone versus concomitant procedures. J Thorac Cardiovasc Surg. 2003;126:1822-8.

7. Guo Y, Lip GY, Apostolakis S. Inflammation in atrial fibrillation. J Am Coll Cardiol. 2012;60:2263-70.
8. Hu YF, Chen YJ, Lin YJ, Chen SA. Inflammation and the pathogenesis of atrial fibrillation. Nat Rev Cardiol. 2015;12:230-43.

9. Frustaci A, Chimenti C, Bellocci F, Morgante E, Russo MA, Maseri A. Histological substrate of atrial biopsies in patients with lone atrial fibrillation. Circulation. 1997;96:1180-4.

10. Chung MK, Martin DO, Sprecher D, Wazni O, Kanderian A, Carnes CA, et al. C-reactive protein elevation in patients with atrial arrhythmias: inflammatory mechanisms and persistence of atrial fibrillation. Circulation. 2001;104 2886-91.

11. Conway DS, Buggins P, Hughes E, Lip GY. Predictive value of indexes of inflammation and hypercoagulability on success of cardioversion of persistent atrial fibrillation. Am J Cardiol. 2004;94:508-10.

12. Tsai FC, Chang GJ, Hsu YJ, Lin YM, Lee YS, Chen WJ, et al. Proinflammatory gene expression in patients undergoing mitral valve surgery and maze ablation for atrial fibrillation. J Thorac Cardiovasc Surg. 2016;151:1673-82.e5.

13. Cox JL, Boineau JP, Schuessler RB, Ferguson TB Jr, Cain ME, Lindsay BD, et al Successful surgical treatment of atrial fibrillation. Review and clinical update. JAMA. 1991;266:1976-80.

14. Cox JL, Schuessler RB, D'Agostino HJ Jr, Stone CM, Chang BC, Cain ME, et al. The surgical treatment of atrial fibrillation. III. Development of a definitive surgical procedure. J Thorac Cardiovasc Surg. 1991;101:569-83.

15. Schulz RA, Yutzey KE. Calcineurin signaling and NFAT activation in cardiovascular and skeletal muscle development. Dev Biol. 2004;266:1-16.

16. Santana LF. NFAT-dependent excitation-transcription coupling in heart. Circ Res. 2008;103:681-3.

17. Ramos-Mondragon R, Galindo CA, Avila G. Role of TGF-beta on cardiac structural and electrical remodeling. Vasc Health Risk Manag. 2008;4:1289-300.

18. Nattel S, Burstein B, Dobrev D. Atrial remodeling and atrial fibrillation: mechanisms and implications. Circ Arrhythm Electrophysiol. 2008;1:62-73. 